\title{
Governmental Planning
}

\author{
Dr. S. B. M. Marume ${ }^{1}$ \\ ${ }^{I}$ BA, Hons BA, MA, MAdmin, MSocSc, PhD Department of Public Administration Zimbabwe Open University
}

\begin{abstract}
According to social scientists, namely; public administration scientists, political scientists, economists, sociologists, students and readers, planning is now viewed and accepted as an indispensible activity in the public sector, as opposed to the ancient point of view that to foretell the future did not reside within the province of humankind's capabilities. As a matter of fact, planning with reference to contemporary thinking is accorded a necessary element in governmental activities, as is evident from the uses of various terms and concepts such as policy planning, development planning, economic planning, social planning, rural planning, urban planning, and governmental planning to mention but a few; and the latter concept, that is, governmental planning, is the subject this article.
\end{abstract}

Keywords: planning, policy planning, economic planning, development planning, indispensable activity, and governmental planning, foretell the future.

\section{Introduction}

From the literature available the term planning is utilized in so many different ways that there is often confusion about what people actually mean when they talk about planning or when they employ terms such as plans and planners.

According to Diana Conyers and Peter Hills (1994:3), moreover, many of its uses are so broad that the basic elements of planning are difficult to identify and it cannot easily be distinguished from related activities, such as policy making, or plan implementation. It was partly this confusion over the uses of the term planning which led one leading writer on the subject to call his article: "If planning is everything, maybe it's nothing" (A. Wildavsky, 1973:127-53).

\section{Purpose Of Article}

The purpose of this article is to remove some of the terminological and semasiological confusion which surrounds the concept planning and, and at the same time, to clarify the way in which we use certain basic terms and concepts related to planning in the rest of this article.

Thus governmental planning in this article is examined from the three folded frame of reference as follows:

- firstly, a terminological analysis;

- secondly, the various steps in the planning process and the locus of planning in public administration; and

- thirdly, various approaches to planning, that is, city and town planning, regional planning, and economic planning.

\section{Governmental Planning}

To comprehend the term governmental planning clearly, a number of propositions need to be examined systematically as follows:

\subsection{Prominent relevant social scientists}

These include:

\begin{tabular}{|l|l|l|}
\hline Diana Conyers & Peter Hills & Albert Waterston \\
A. H. Hansen & R. W. Riggs & A. Wildavsky \\
J. D. Millet & S. X. Hanekom & R. W. Rowland \\
E.G. Bain & R. S. Basi & G. R. S. Brown \\
D. R. Stell & E. N. Gladden & F. M. Marx \\
C. G. Kling & B. J. roux & J. J. N. Cloete \\
F. A Von Hayek & Barbara Woottom & S.B. M. Marume \\
\hline
\end{tabular}

\subsection{Terminological aspects of planning}

The term "planning" is a controversial work and has been the object of bitter denunciation and enthusiastic endorsement by its antagonists and protagonists respectively (J. D. Millet, 1947:1). Planning manifests as a means towards a variety of purposes or goals, which promotes its highly diverse usage; from the preparation and execution of space programmes to endeavors such as governing a city, a region, or a nation. It can be temporary, transitory, and seasonal in its focus, for example, planning after a natural disaster and during 
post-war reconstruction, or it may be more long term, for instance, national planning for economic stability, full employment or economic development. Moreover, planning is a pervasive phenomenon in all goal oriented human activity regardless of the particular kind of economy, society, or political system. (A. Waterston, 1969: 8 - 9) After all this debate, the question still remains, namely, what is planning? Several viewpoints of planning are given as follows: Planning is deciding in advance what to do, how to do it, when to do it, and who is to do it. (Hanekom, Rowland and Bain, 1993:43)

Planning may be seen as identifying the pertinent factors in a situation and relating them to the process of evolving a course of action believed to be the best to achieve desired results. (R. S. Basi, 1968:21) Most leading development planning experts view planning as an organized, intelligent attempt to select the best available alternatives to achieve specific goals. (Waterston, 1969:8). According to E.G. Bain, one of the most contemporary southern African public Administration scientists, planning is seen as a process used for the selection from various alternatives of a way of action to give effect to broad policy guidelines (Hanekom, Rowland and Bain, 1993:46).

Brown and Steel, both British writers on public administration, maintain that:

To plan is to look ahead and try and foresee the consequences of actions and trends in events instead of taking a series of ad hoc, uncoordinated decisions. (Brown and Steel, 1979:238)

E.H. Gladden, one of the prominent British public administration scientists, sees planning as an essential phase in. or aspect of, any human activity which calls for forward looking attitudes (E. N. Gladden, 1972: 220). From the above it can be deduced that planning is:

a) an intellectual activity;

b) future oriented;

c) a process;

d) generic in nature;

e) goals oriented;

f) a choice between alternatives.

Conyers and Hill (1994:3) view the working definition of planning as a continuous process which involves decisions, or choices, alternative ways of using available resources, with the aim of achieving particular goals at some time in the future.

\section{Summary of definition of planning}

To summarise the various definitions of the term and concept of planning, it may be useful to say:

- to plan means to choose;

- planning involves making decisions about which of a number of courses of action to adopt in other words, making choices;

- planning as a means of achieving goals;

- planning for the future and

planning as a systematic and continuous process which involves decisions, or choices, about alternative ways of using available resources, with the aim of achieving particular goals at some time in the future; and the concept resource includes not only natural resources such as land, water, mineral wealth and so on but also manpower (or human resources), capital resources such as roads, buildings and equipment and finances. Moreover, it also recognizes that the definition of what is and what is not a resource may vary, depending on the user's objective and his perception of its value and his ability. Planning involves decision about how to make the best use of the available resources. Consequently, the quantity and quality of these resources has a very important effect on the process of choosing between different courses of action. On the one hand, the fact that there are almost ways limits to the quantity and quality of resources available, is the main resources why planning involves deciding which of a number of desirable courses of action should be given priority. On the basis of the above assumptions, a definition of planning may be evolved as follows: The planning process is of a generic nature intended to visualize a future state of affairs by choosing between alternatives towards goal realization, and is in effect the result of an intellectual activity (Hanekom, Rowland and Bain, 1993:46).

\subsection{Steps in the planning process}

Planning as a comprehensive process may be seen as consisting of certain actions which apply equally well to all types of planning regardless of the particular endeavour; in other words, it is an auxiliary phenomenon present in all goal - oriented human behaviour.

Christian Kling, an American planning scientist, has identified seven steps in the planning process:

\subsubsection{Seven identified steps}

a) identification of needs;

b) identification of clients; 
c) value formulation;

d) development of goals;

e) means identification, that is, identifying objectives, weighing alternatives, and making a recommendation;

f) implementation - effectuation; and

g) monitoring (Christian G. Kling, 1976: 7 - 10)

\subsubsection{Classification of steps}

B. J. Roux, one of the most celebrated southern African public administration scientists of our time, has made a classification, which generally agrees with that of C. G. Kling although in somewhat different terms, consisting of the following action:

(a) assistance and advice to policy-making on the formulation of policy by means of:

- surveys and data collection,

- identification of variables,

- determination of alternatives and

- forecasts;

(b) assistance and advice to policy-makers on the definition of intermediate and ultimate goals;

(c) the systematic plotting by means of the techniques under (a) of a course of action and estimates, recommendations and decisions on what will be required in terms of the enabling administrative functions that is,:

- organisation,

- $\quad$ personnel (provision, utilisation, maintenance and training)

- finance,

- work methods and procedures,

- control, and

- external relations;

(d) repetition of any or all of the foregoing steps, usually on a smaller scale as often process of implementation. (B. J. Roux 1968:148-9).

The successive steps to put these above actions into operation may be depicted as in figure 1. Although these steps are linked to a macro-perceptual context, that can also be applied in a micro-perceptual context. Obviously, as minor plans are usually less complicated, certain of the steps are more easily accomplished, but this does not negate the fact that they are of general application.

Figure 1. Successive steps in the planning process

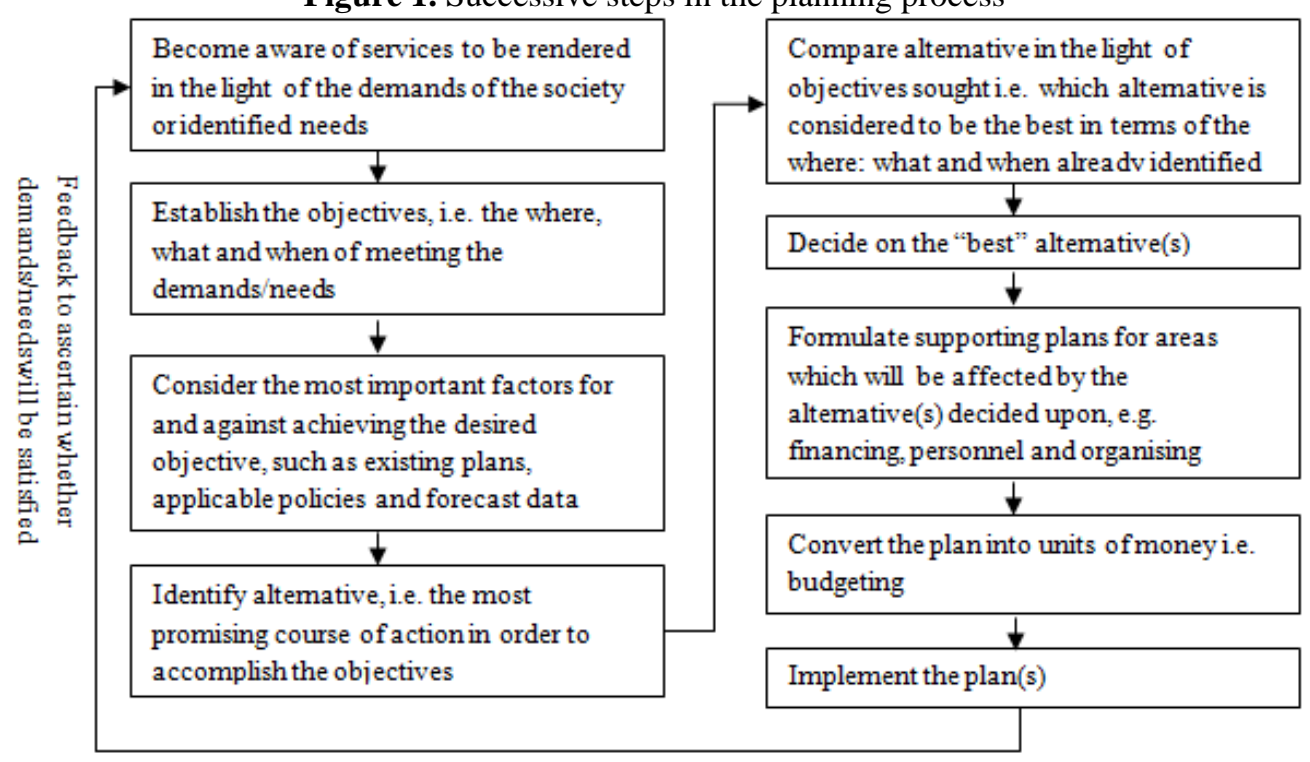

\subsubsection{Locus of planning: superior or subordinate}

Literature on planning reveals a variety of usages of the term linked to the term linked to the area on which planning is focused. The following examples will suffice:

1. public expenditure planning

2. departmental planning systems

3. planning in government 
4. planning and politics (Brown and Steel, 1979:240 - 60)

5. wartime planning

6. town and country planning

7. anticyclical planning

8. planning in a pluralistic society

9. development planning (Waterston, 1969:10 - 15)

10. policy planning

11. programme planning

12. planning for national security

13. military planning (Marx, 1959: 114 - 126).

The planning process is a generic phenomenon. Although agreement has been reached on the generic nature of planning, the question as to whether it is superior or subordinate to other administrative functions still remains unresolved. Two distinct views can be identified in this regard.

Firstly, planning is considered to be prius inter pares (first among equals) in a time context in that it precedes and pervades other administrative functions. This primary of planning can be depicted as in Figure 2

Figure 2

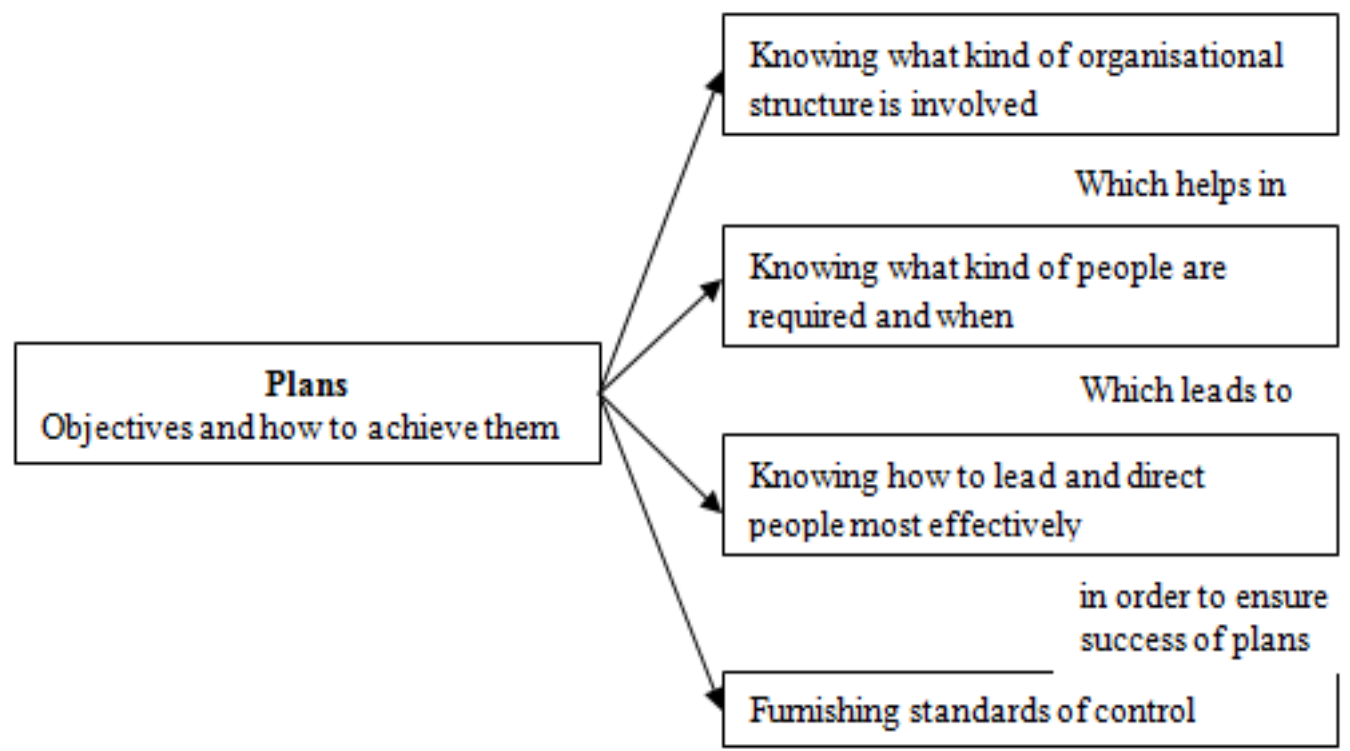

Although Figure 2 applies to the private sector, it holds equally well for planning in the public sector. Marx, a classical American public administration scientist, for instance maintains that is preparation for action, a means to formulating the objectives to be realized by executive institutions, and in the process of the formulation of objectives decisions are taken on administrative functions such as:

- $\quad$ organisational arrangements;

- financial requirements;

- personnel needs;

- control measures, and

- $\quad$ work processes (Marx, 1959:113)

Since the activity which precedes the announcement of the objective is known as policy-making (Cloete, 1981:57) it following that policy-making and planning dovetail in their focus. Another school of thought maintains policies are also plans in that both are statements of intent which guide or channel thinking and action.

Furthermore, since planning pervades other administrative functions, it has come to be associated with them in the following ways:

- policy planning

- $\quad$ organisational planning;

- financial planning

- manpower planning;

- procedural planning; and

- control planning (Hanekom and Bain, 1993:49). 


\section{Figure 3}

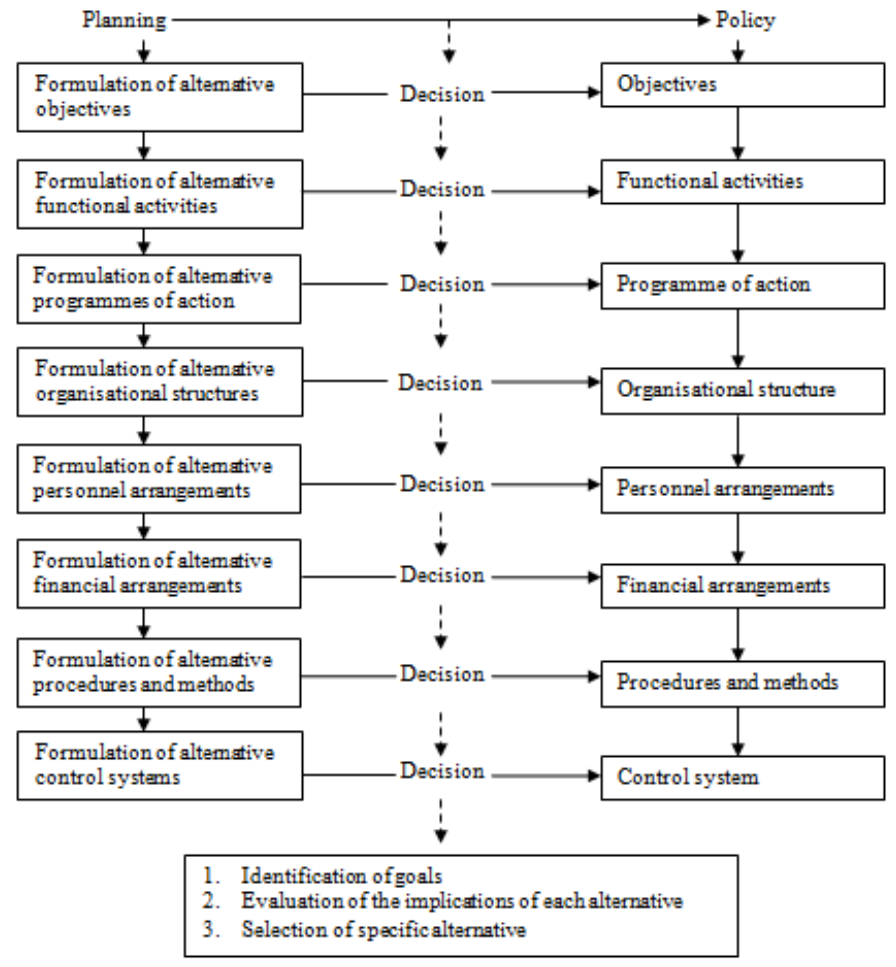

The second view of the locus of planning considers planning to be an auxiliary process secondary to the policy-making process. Professor Cloete, the founder of the most popular generic theory of public administration, suggests that in the public sector, consisting of a variety of institutions and fields of activity, planning must be of a necessity follow policy-making, because only after a policy directive has been obtained can planning be undertaken (Cloete: 1981:2). Thornhill, (1993:50 one of the modern South African public administration scientist, echoes this view by stating that the framework for governmental actions is found in a policy and that planning will necessarily follow on from it. In this sense, planning activities are put in a reverse relationship with policy-making as compared to the first exposition in that planning has a policy objective, which has been identified and described by means of a policy statement as a prerequisite.

Diagrammatically this view can be depicted as in Figure 4.

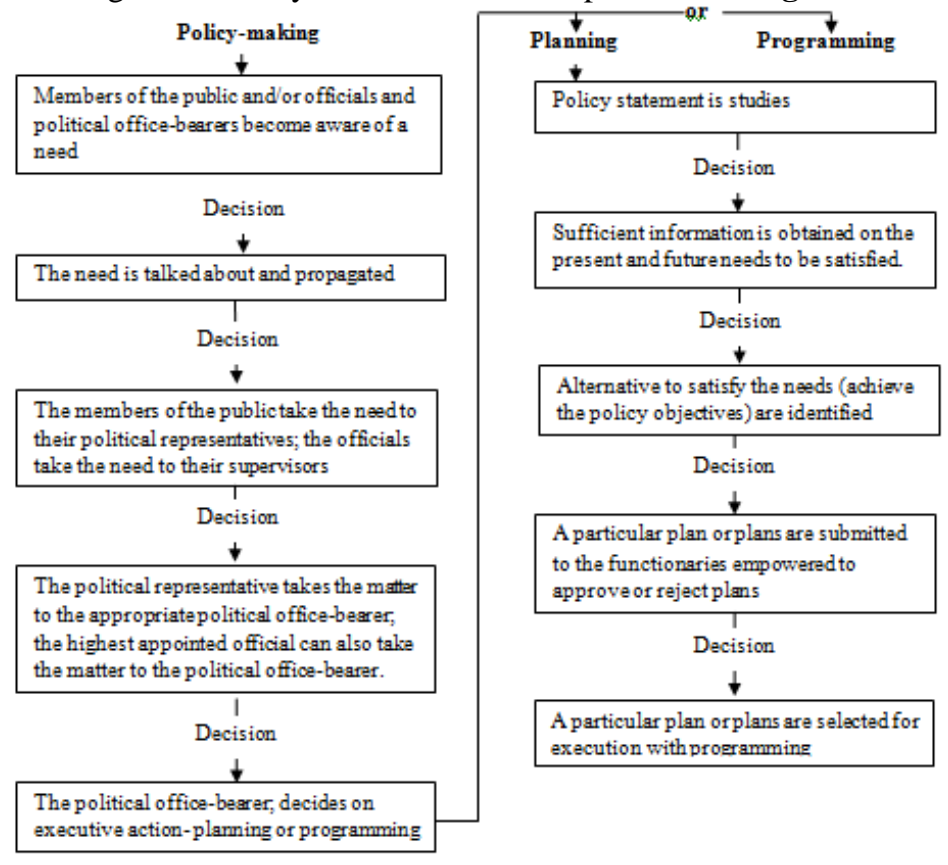




\subsubsection{Approaches to planning}

It has to be clearly understood that planning has been developed as a governmental function through which states can pursue the orderly attainment of identified goals.

\subsubsection{City and town planning}

City and town planning can be regarded as the oldest manifestation of government planning; the orderly development of community life was carried on in the so-called city - states of ancient Greece, which are the oldest form of organized government. History shows that western civilization and democracy developed from a system of local government in local communities in which every citizen participated. Originally planning was limited to the physical or spatial environment in the city plans focused on aspects such as defence or the city's beautification. However, the history of public administration provides another example of city planning as early as $1500-1400 \mathrm{BC}$.

According to Professor Cloete, city plans, initially focused on the physical development, for instance, plans for defence against invaders, for places of worship or for the city's beautification, whereas points of emphasis during later years were the provision of community facilities such as roads, the control of land use, water provision, and electricity. In addition, inhabitants were granted the opportunities to benefit spiritually, for example by guarding against the development of slums and the provision of facilities for recreation, health, education and the arts (Cloete: 1981:op. cit)

In South Africa, Zimbabwe, Zambia, for instance, until World War II, the physical planning was confined to the larger city centre where town planning was in operation. Outside these centre planning was restricted to the purchase of land by certain race groups outside their traditional areas. Presently urban planning is responsibility of provincial and local governments with the assistance of statutory guide plan committees appointed in terms of the Environment Planning Act, 1967 (Act No. 88 of 1967 as amended by Act No. 73 of 1975, in the case of South Africa).

Guide - plan communities were already established in 1971 following the recommendation of the NIEMAND Commission investigation into the excessive prices of residential stands in urban areas, but they functioned without statutory authority. Guide- plan communities do not diminish the planning function of provincial or local government authorities; they are coordinating institutions and merely assist on streamlining recommendations submitted to them. Coordination is enhanced in that guide - plan committees act as forums where interested parties from central, provincial and local authorities and from the private sector can deliberate.

\subsubsection{Regional planning}

Closely linked to city and town planning but larger in scope and nature, is regional planning, by which modern states coordinate town planning, on the one hand, and national planning, on the other hand, according to the differing needs of various areas in the country as a whole. The ripple effect of city development, that is, the outward movement of town clusters in to cities, metro-poles, mega-poles and ultimately regions of development, pose new challenges to physical planners who have increasingly encountered problems whose solution is dependent on decisions made on a regional planning basis. Planning activities on a regional basis may be aimed, amongst other things, towards social upliftment, interrelated physical development and economic development.

Professor Waterson (1969:13) one of the leading American development planning scientist, notes that because regional planning depends on decisions involving the economy of the region in which the subdivided parts operate, physical planning of a region has become increasingly concerned with problems usually restricted to economic planning. One of the most difficult problems of regional planning is the delimitation of areas. Delimitation can be approached from various viewpoints, for instance, existing boundaries, communal, interests groups, areas for the best utilization of specific resources, for example, water, climatic regions.

Regional planning may be sub-national, or multinational. Sub-national regional planning may refer to:

- the planning of cities in various forms or of a depressed part of a country.

- the preparation of a series of regional pans covering on entire country with a view to preparing a national plan;

- the distribution of projects to certain regions as part of a national plan.

Multinational regional planning may refer to:

- planning for a region which extends beyond the boundaries of one country;

- planning for one or more regions of two or more countries;

- coordination of national plans for the entire economies of several counties to an international regional institutions (Waterson, 1969: 22- 24) 


\subsubsection{Economic planning}

In order to plan for economic purposes actions should be directed towards the mobilization of economic resources to maintain a specific economic growth rate, to realize socialistic aims, inter alia, the prevention of unemployment and the upliftment of the Standard of living through the mobilization of economic changes. Economic planning in the public sector refers to governmental action to ensure the economic welfare of the community. It can be either to restrain or to encourage the economic activities of the private as well as the public sectors.

The successes gained by Russia, as well as the adverse effects of the Second World War on western economics, prompted governments to take an interest in governmental economic planning. However, despite the successes of the Russian five - and seven- year plans, the abuses of Russian commotions, fascism and eventually Nazism resulted in an intense controversy between the opponents and supporters of western economic planning, the key personalities being F. A. von Hayck and Barbara Wootton respectively.

Hayek argues that planning as a means to attain socialistic goals might lead to the destruction of democracy which would inevitably result in the oppression of citizens. Wootton on the other hand, regards planning as the hub of orderly production and argues that it should be undertaken in conjunction with socialism. At present western countries generally accept that planning is an important aid to government decisions affecting long - term socio- economic development.

\section{Summary}

Planning which can be identified as a pervading phenomenon in all human activities, can be described as a generic process intended to determine a future state of affairs buy choosing between alternative towards goal realization. Planning may be seen as consisting of certain steps which political office- bearers as well as public officials have to bring to bear to direct activities towards an anticipated model of action. Planning may either precede or follow on policy - making in order to give direction to governmental activities as implied by its generic nature. The approaches identified for the purposes of this discussion can be classified into city and town planning, regional planning and economic planning.

\section{Bibliography}

[1]. R. S. Basi: Action administration: planning and implementation, London, Asia Publishing House, 1968.

[2]. G. R. S. Brown and D.R. Steel: The administrative process in Britain, London, Methuen and Company Limited, 1979.

[3]. J. J. N. Cloete: Introduction to Public Administration: Pretoria, J. L. van Schaik, 1981.

[4]. E. N. Gladden, Central government administration, London, staples Press, 1972

[5]. E. N. Gladden, A history of public administration, London, Frank Cass, Volume 1, 1972

[6]. Christina G. Kling, Principles of urban planning, New York, Vantage Press, 1976

[7]. S. B. M. Marume: Epistemological and methodological aspects of African social research studies: unpublished PhD (Public work No. 17: California University for Advanced Studies, State of California: September 30, 1988).

[8]. F. M. Marx (ed): Elements of public administration, Englewood Cliffs, New Jersey, Prentice-Hall, Inc., 1959.

[9]. J. D. Millet, The process of organisation of government planning, New York, Columbia University Press, 1947.

[10]. B. J. Roux, "The planning process - a generic view, provisionally stated" in SAIPA, Journal of Public Administration, volume 3, No. 10, January 1968.

[11]. Albert Waterson, Development planning: lessons of experience, Baltimore, John Hopkins Press, 1969.

\section{Profile of contributor and photograph}

Samson Brown Muchineripi Marume: a former senior civil servant for over 37 years serving in various

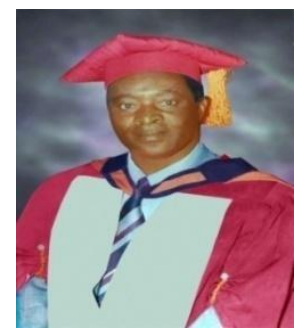
capacities of seniority and thirteen years as deputy permanent secretary; thirteen years as a large commercial farmer; well travelled domestically within Zimbabwe; regionally [SADC countries: Angola, Botswana, Lesotho, Malawi, Mozambique, Mauritius, Swaziland, South Africa, Namibia, Tanzania, Zambia and DRC]; and Africa [Kenya, Ethiopia, Sudan, Egypt, Nigeria, Ghana, Libya, and Uganda]; and internationally [Washington, New York and California in USA; Dublin and Cork in Ireland; London in England in United Kingdom; Netherlands, Frankfurt in Germany; Lisbon in Portugal; Spain (Nice), Paris in France, Geneva in Switzerland, Belgrade in former Yugoslavia-; Rome and Turin in Italy; Nicosia - Cyprus; Athens - Greece; Beijing and Great Walls of China; Singapore; Hong Kong; Tokyo, Kyoto, Yokohama, and Osaka, in Japan]; fifteen years as management consultant and part - time lecturer for BA/BSc and MA/MBA degree levels with Christ College- affiliate of Great Zimbabwe University and National University of Science and Technology; six years as PhD/DPhil research thesis supervisor, internal and external examiner with Christ University, Bangalore, India [2010 - 2016], and Zimbabwe Open University; external examiner of management and administrative sciences at Great Zimbabwe University (2016 - 2019); currently senior lecturer and acting chairperson of Department of Public Administration in Faculty of Commerce and Law of Zimbabwe Open University; a negotiator; a prolific writer as he has published five books, prepared thirty modules in public administration and political science for undergraduate and postgraduate students, and over seventy referred articles in international journals [IOSR, 
IJSR, ISCA - IRJSS, IJESR, IJESI, IJBMI, IJHSS and Quest Journals] on constitutional and administrative law, public administration, political science, philosophy, Africa in international politics, local government and administration, sociology and community development; vastly experienced public administrator; and an eminent scholar with specialist qualifications from University of South Africa, and from California University for Advanced Studies, State of California, United States of America: BA with majors in public administration and political science and subsidiaries in sociology, constitutional law and English; postgraduate special Hons BA [Public Administration]; MA [Public Administration]; MAdmin magna cum laude in transport economics as major, and minors in public management and communications; MSoc Sc cum laude in international politics as a major and minors in comparative government and law, war and strategic studies, sociology, and social science research methodologies; and PhD summa cum laude in Public Administration. 